\title{
Modes of Binding Interaction Between Viologen Guests and the Cucurbit[7]uril Host
}

Kwangyul Moon and Angel E. Kaifer*

Center for Supramolecular Science and Department of Chemistry, University of Miami, Coral Gables, FL 33124-0431.

\section{Supporting information}

Diffusion coefficient of guest molecule

Guest : Ethylviologen

Host: CB7

Solvent: $0.2 \mathrm{M} \mathrm{NaCl}$ in $\mathrm{D}_{2} \mathrm{O}$

Instrument: $500 \mathrm{MHz} \mathrm{NMR}$

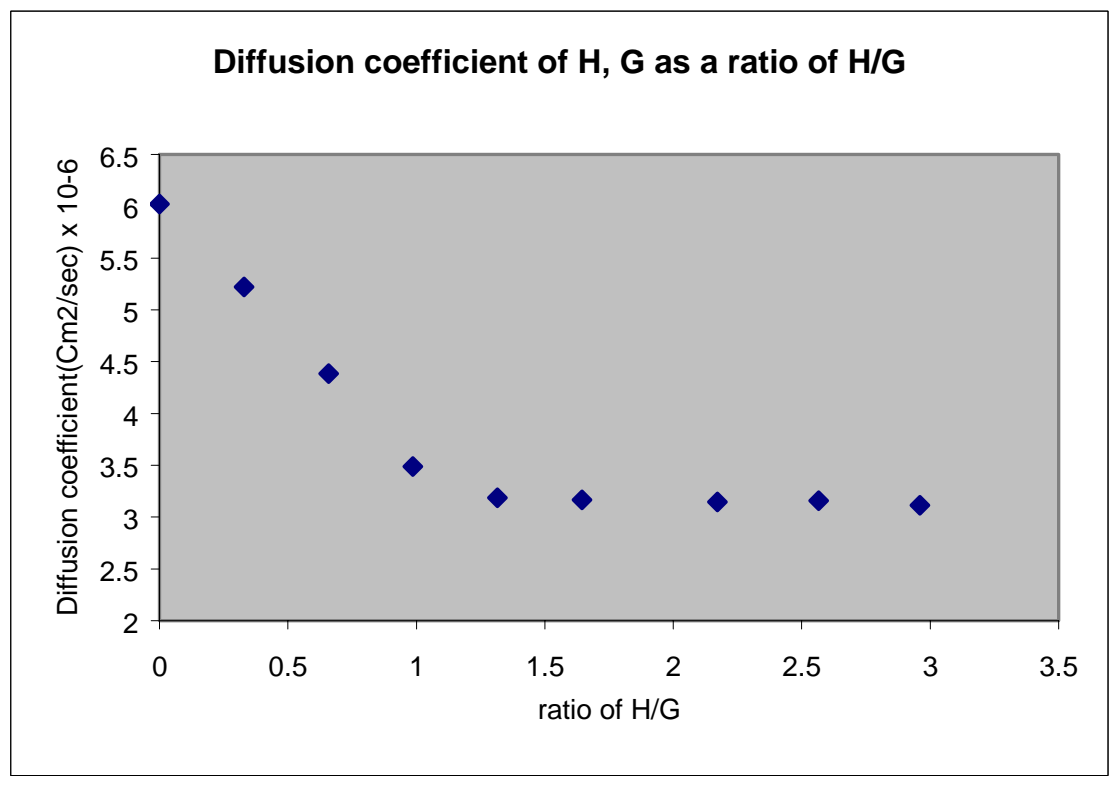


NMR titration of propylviologen with CB7

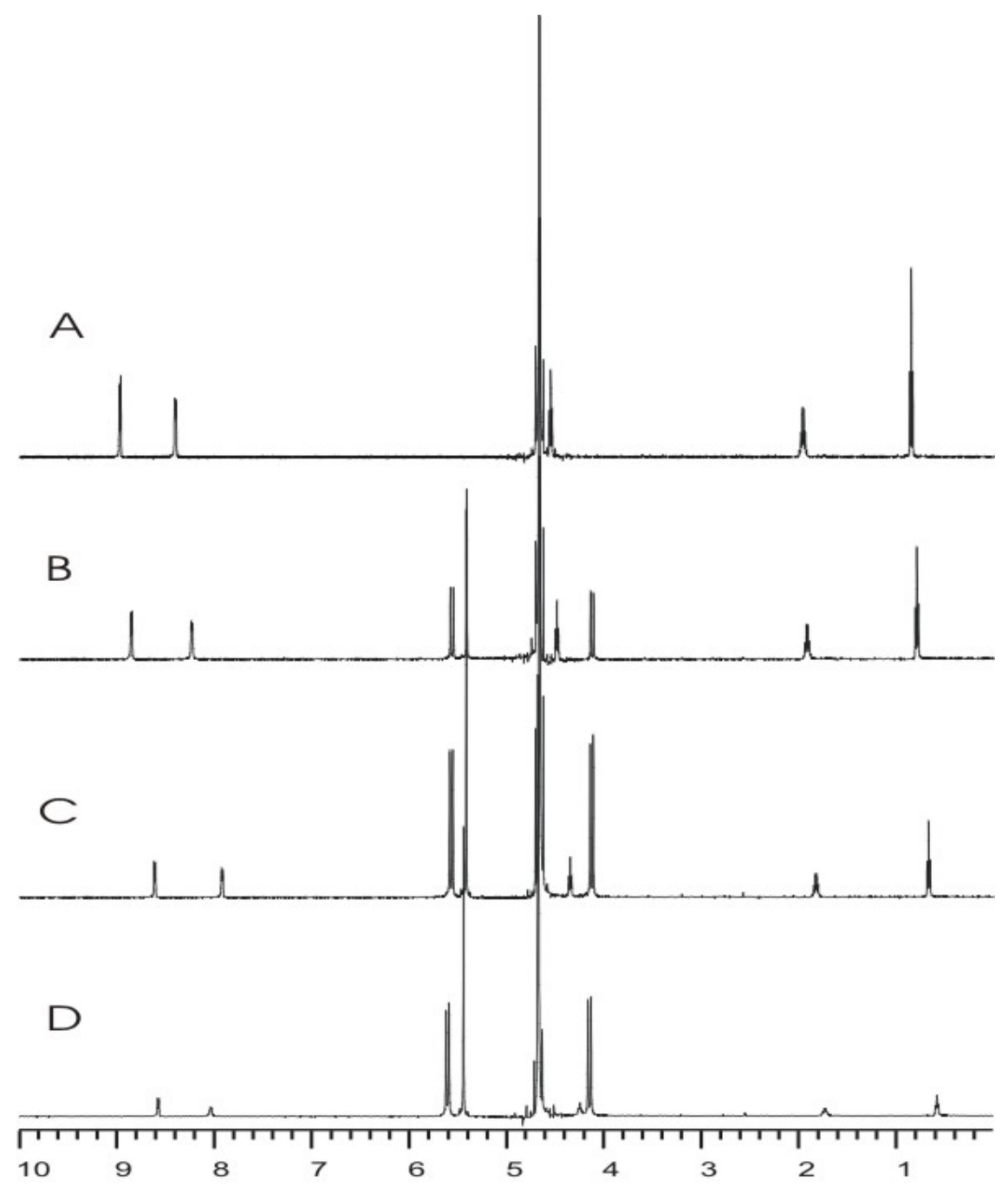

Solvent : $0.2 \mathrm{M} \mathrm{NaCl}$ in $\mathrm{D}_{2} \mathrm{O}, 500 \mathrm{MHz}$
A: propylviologen
B: addition of CB7 (0.34eq)
C: addition of CB7 (1.03eq)
D: addition of CB7 (1.72eq) 
NMR titration of butyl viologen with CB6

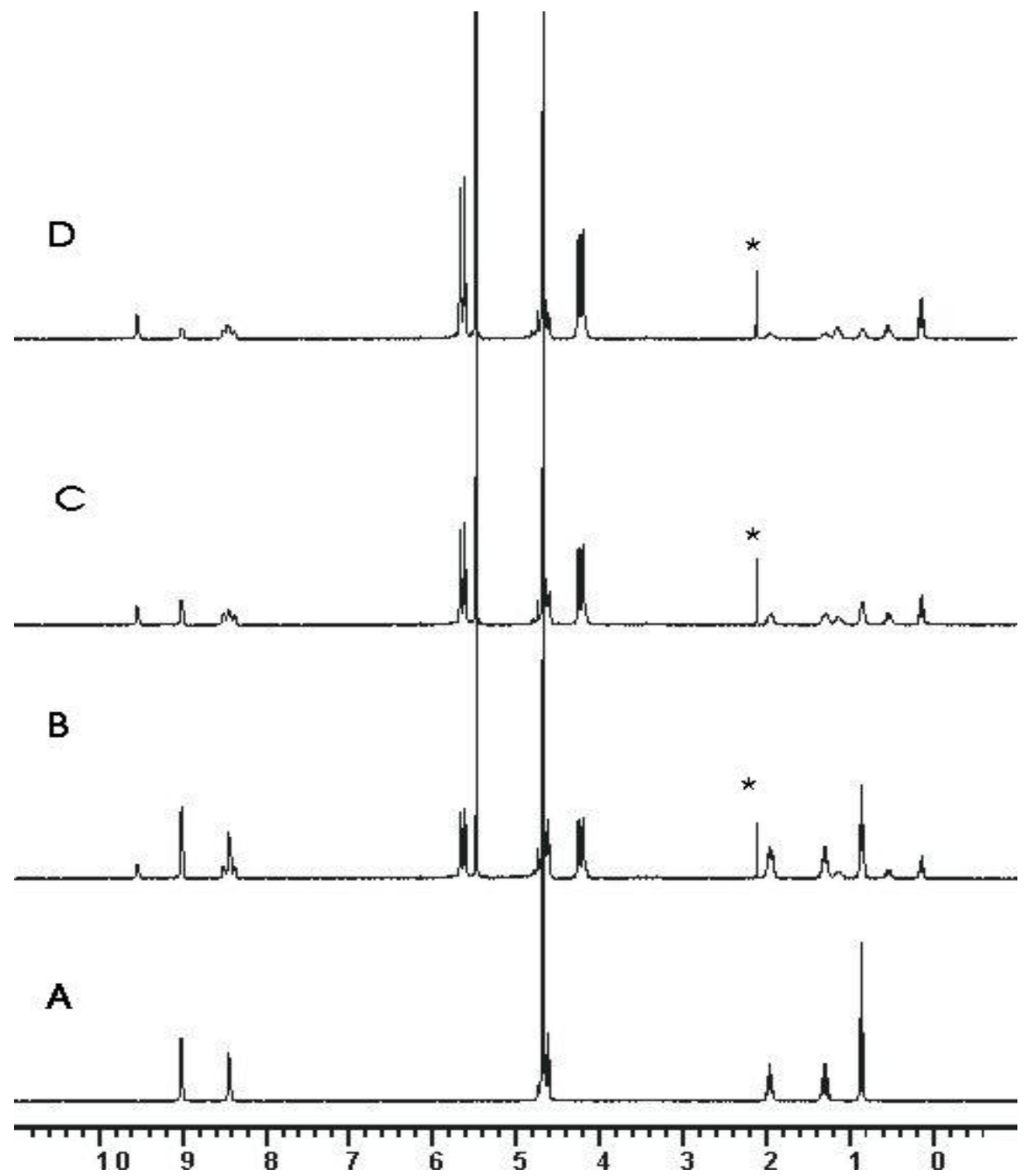

Solvent : $0.2 \mathrm{M} \mathrm{NaCl}$ in $\mathrm{D}_{2} \mathrm{O}, 300 \mathrm{MHz}$

A : butyl viologen

$B$ : addition of CB6 (0.5eq)

$\mathrm{C}$ : addition of CB6 (1.0eq)

$\mathrm{D}$ : addition of CB6 (1.5eq)

Asteric is a solvent (acetone) 
NMR titration of heptylviologen with CB7

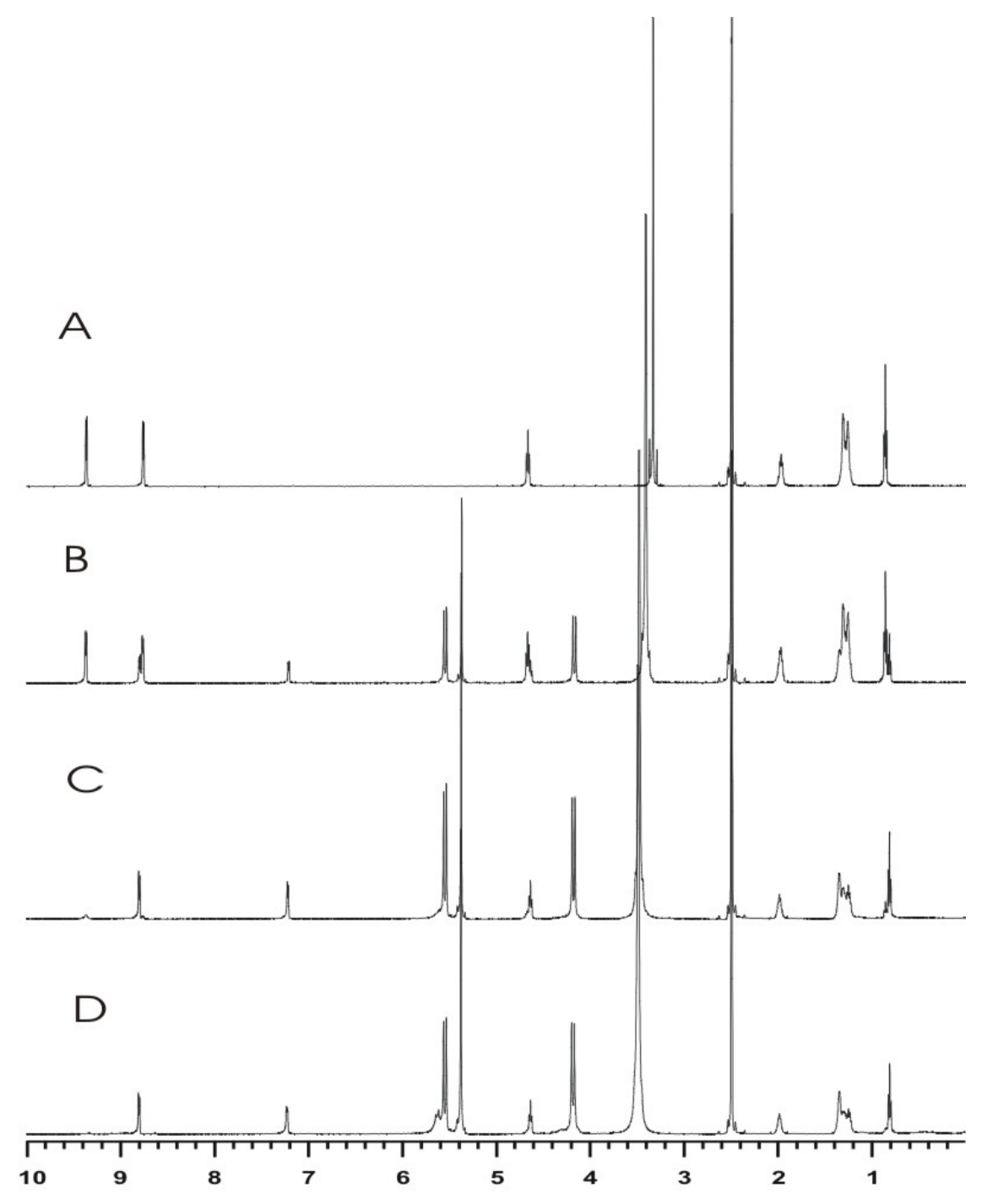

Solvent : DMSO-d 6 , $500 \mathrm{MHz}$
A: heptyl viologen
B: addition of CB7 (0.4eq)
$\mathrm{C}$ : addition of $\mathrm{CB} 7$ (1.05eq)
D: addition of CB7 (1.4eq) 
NMR titration of amino-dinitrophenyl-propyl viologen with CB7

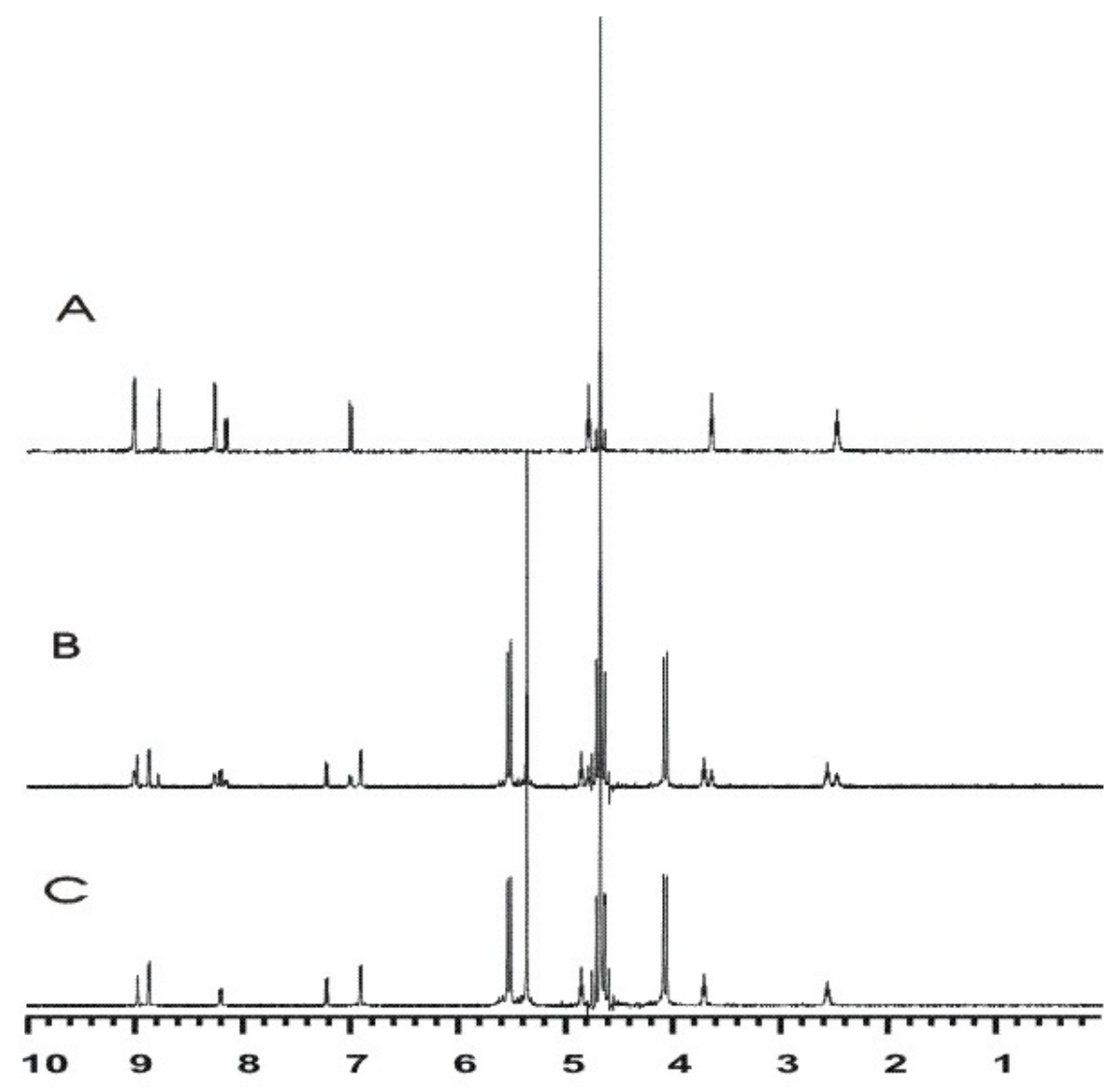

Solvent : $\mathrm{D}_{2} \mathrm{O}, 500 \mathrm{MHz}$

A: amino-dinitrophenyl-propyl viologen

B: addition of CB7 (0.66eq)

C: addition of CB7 (1.09eq) 


\section{General procedure for the synthesis of bis(alkyl)viologens}

A mixture of 4,4'-dipyridyl (1.0 equiv) and the corresponding alkyl bromide (8 equiv) in $\mathrm{CH}_{3} \mathrm{CN}$ was refluxed for 3 days. The resulting precipitate was filtered, washed with hot chloroform to remove monoalkylated product and dried under vacuum.

${ }^{1} \mathrm{H}$ NMR of $\mathbf{E V}^{2+}\left(500 \mathrm{MHz}, 0.2 \mathrm{M} \mathrm{NaCl}-\mathrm{D}_{2} \mathrm{O}\right) \oint(\mathrm{ppm}) 8.99(\mathrm{~d}, \mathrm{~J}=5 \mathrm{~Hz}, 4 \mathrm{H}, \alpha$ of viologen $), 8.40$ (d, J=5Hz, 4H, $\beta$ of viologen), 4.61 (q, 4H, $\left.\mathrm{CH}_{2}\right), 1.55\left(\mathrm{t}, 6 \mathrm{H}, \mathrm{CH}_{3}\right)$, MASS (FAB): $214\left(\mathrm{M}^{+}\right.$)

${ }^{1} \mathrm{H}$ NMR of $\mathbf{P V}^{2+}\left(500 \mathrm{MHz}, 0.2 \mathrm{M} \mathrm{NaCl}-\mathrm{D}_{2} \mathrm{O}\right) \oint(\mathrm{ppm}) 8.98(\mathrm{~d}, \mathrm{~J}=6 \mathrm{~Hz}, 4 \mathrm{H}, \alpha$ of viologen $), 8.41$ (d, J=6Hz, $4 \mathrm{H}, \beta$ of viologen), $4.56\left(\mathrm{t}, 4 \mathrm{H}, \mathrm{CH}_{2}\right), 1.96\left(\mathrm{~m}, 4 \mathrm{H}, \mathrm{CH}_{2}\right), 0.85\left(\mathrm{t}, 6 \mathrm{H}, \mathrm{CH}_{3}\right), \mathrm{MS}$ (FAB): $242\left(\mathrm{M}^{+}\right)$

${ }^{1} \mathrm{H}$ NMR of $\mathbf{B V}^{2+}\left(300 \mathrm{MHz}, 0.2 \mathrm{M} \mathrm{NaCl}-\mathrm{D}_{2} \mathrm{O}\right) \oint(\mathrm{ppm}) 9.01(\mathrm{~d}, \mathrm{~J}=6.3 \mathrm{~Hz}, 4 \mathrm{H}, \alpha$ of viologen ), $8.44(\mathrm{~d}, \mathrm{~J}=6.3 \mathrm{~Hz}, 4 \mathrm{H}, \beta$ of viologen $), 4.60\left(\mathrm{t}, 4 \mathrm{H}, \mathrm{CH}_{2}\right), 1.95\left(\mathrm{~m}, 4 \mathrm{H}, \mathrm{CH}_{2}\right), 1.30\left(\mathrm{~m}, 4 \mathrm{H}, \mathrm{CH}_{2}\right)$, 0.85(t, $\left.6 \mathrm{H}, \mathrm{CH}_{3}\right), \mathrm{MS}(\mathrm{FAB}): 270\left(\mathrm{M}^{+}\right)$

\section{Synthesis of $\mathbf{N H V} \cdot\left(\mathbf{P F}_{\mathbf{6}}\right)_{2}$}

A mixture of 4,4'-dipyridyl $(2 \mathrm{~g}, 12.8 \mathrm{mmol})$ and 3-bromopropylamine hydrobromide $(7 \mathrm{~g}$, $52 \mathrm{mmol}$ ) in $\mathrm{CH}_{3} \mathrm{CN}$ was refluxed for 3 days. . The resulting precipitate was filtered and dissolved in water. The solution was treated with $\mathrm{NaOH}$ solution until the blue color characteristic of reduced viologen appeared. $\mathrm{NH}_{4} \mathrm{PF}_{6}$ was added to the solution to exchange the counter anions. The resulting solid was filtered, washed with water, THF and dried under vacuum. Yield : 59\%, (4.25g, $7.56 \mathrm{mmol})$.

${ }^{1} \mathrm{H} \mathrm{NMR}$ of $\mathrm{NHV}^{2+}\left(300 \mathrm{MHz}, 0.2 \mathrm{M} \mathrm{NaCl}-\mathrm{D}_{2} \mathrm{O}\right) \oint(\mathrm{ppm}) 9.05$ (d, J=6.6Hz, 4H, $\alpha$ of viologen ), $8.47(\mathrm{~d}, \mathrm{~J}=6.6 \mathrm{~Hz}, 4 \mathrm{H}, \beta$ of viologen $), 4.71\left(\mathrm{t}, 4 \mathrm{H}, \mathrm{CH}_{2}\right), 2.88\left(\mathrm{t}, 4 \mathrm{H}, \mathrm{CH}_{2}\right), 2.29\left(\mathrm{~m}, 6 \mathrm{H}, \mathrm{CH}_{3}\right), \mathrm{MS}$ (FAB): $272\left(\mathrm{M}^{+}\right)$

\section{Synthesis of $\mathbf{N H D B V} \cdot\left(\mathrm{PF}_{6}\right)_{2}$}

A mixture of aminopropyl-viologen hydrochloride (185mmg, 0.444mmol) and 2,4,6-collidine $(0.74 \mathrm{~mL})$ in water $(2 \mathrm{~mL})$ was stirred at room temperature. A solution of 2,4-dinitro fluorobenzene in $\mathrm{CH}_{3} \mathrm{CN}(2 \mathrm{~mL})$ was added to the first solution. The reaction was stirred for $20 \mathrm{~h}$ at room temperature. The resulting solid was filtered, washed with water, THF, ether and dried under vacuum. Yield : $81 \%,(243 \mathrm{mg}, 0.36 \mathrm{mmol})$. Counter ion exchange of the product was accomplished by treatment with excess $\mathrm{NH}_{4} \mathrm{PF}_{6}$.

${ }^{1} \mathrm{H}$ NMR of NHDBV $^{2+}\left(\mathrm{DMSO}_{-}, \mathrm{d}_{6}, 500 \mathrm{MHz}\right) \oint(\mathrm{ppm}) 9.37$ (d, J=6.5Hz, 4H, $\alpha$ of viologen ), 8.85 (t, 2H, Ar), 8.84 (s, 2H, NH), 8.73 (d, J=6.5Hz, 4H, $\beta$ of viologen), 8.28 (dd, 2H, Ar), 7.27 (d, J=10, 2H, Ar), $4.76\left(\mathrm{t}, 4 \mathrm{H}, \mathrm{CH}_{2}\right), 3.67\left(\mathrm{~m}, 4 \mathrm{H}, \mathrm{CH}_{2}\right), 2.36\left(\mathrm{~m}, 4 \mathrm{H}, \mathrm{CH}_{2}\right)$

${ }^{13} \mathrm{C}$ NMR (DMSO-d 6 , 500MHz) $\oint(\mathrm{ppm}) 148.47,147.86,147.73,145.99,134.98,130.14$, 129.87, 126.30, 123.49, 115.22, 58.972, 29.36.

MS (FAB): $605\left(\mathrm{M}+\mathrm{H}-2 \mathrm{PF}_{6}\right)^{+}, 750\left(\mathrm{M}^{-\mathrm{PF}_{6}}\right)^{+}$ 